\title{
A Practical Research on Digital Electronic Technology Classroom Teaching Based on CDIO Concept Combination of Micro-lecture
}

\author{
GuoQin Zhang ${ }^{1, a^{*}}$ \\ ${ }^{1}$ Zhejiang University of Water Resources and Electric Power, Hangzhou, Zhejiang, China \\ azhgq@zjweu.edu.cn \\ *The Corresponding author
}

\section{Keywords: Digital Electronic Technology; CDIO; Micro-lecture; Classroom Teaching}

\begin{abstract}
In the internet+ age, we have no choice but to rethink classroom teaching reform. There are five problems in the traditional digital electronic technology classroom teaching. Due to the nature of curriculum- engineering and practicality, the digital electronic classroom teaching based on the CDIO concept can solve the shortcomings of the traditional classroom teaching. We put forward how to integrate the network micro-lecture closely based on the CDIO concept to improve the enthusiasm and creativity of students and how to organize the classroom specifically and how to evaluate. Practice has proved that based on the CDIO concept, and integration of the micro-lecture in digital electronic technology classroom teaching can stimulate students' interests and the effects of classroom teaching are good.
\end{abstract}

\section{Introduction}

Today, with the help of the Internet and information and communications technology, there have been new policies, new forms and new models about teaching, such as MOOCs, micro-lectures and flipped classroom. Related academic researches and teaching practices are increasing. With the "Internet +" action was written in the government report in 2015 in China, "Internet + education" has become a new focus. How to use the innovative achievements of the internet to improve the quality of school education is the question that every educator cannot avoid. With the development of information technology, let us have no choice but to rethink the reform of classroom teaching. The program of digital electronic technology is the core curriculum in some professional of electrical, instrumentation, automation and electronic information. Through the learning and training in this program, on the one hand students have to be familiar with the basic knowledge, means and application of digital electronic technology and get the necessary digital electronic technology and general skills. On the other hand, it lays a solid foundation for students to learn the follow-up expertise and professional skills. It is a combination of theoretical and engineering practice program. Relying on limited classroom teaching time only, we cannot only teach the theoretical knowledge fully but also have enough time to practice. In addition, the current social demand is also increasing for graduate employment, especially for practical ability. Based on above problem, we consider the use of internet multimedia technology to provide a greater amount of teaching information to improve the existing teaching model.

\section{The Problems in Traditional Digital Electronic Technology Classroom Teaching}

The Teaching Organization is Not Conducive to the Theory with Practice. Instructors teach theories in the classroom and instruct experiments in the laboratory, and most of experiments are verified. They are not only without the characteristics of actual electronic products, but also the continuity of content and the promotion of the classroom teaching from experiments cannot be guaranteed.

The Arrangement of Teaching Content is Not Easy to Clear the Purpose of Learning for Students. Traditional teaching takes more emphasis on the contents systematic and does not match the actual production process. It is easy to ignore the practical application of knowledge, so that 
there is the divorce between theory and practice, resulting in the purpose of learning is not clear. It is not conducive to solving practical problems.

The Training of Teamwork Capacity is Lack. The learning of theory is major in traditional digital electronic technology. The number of experiments is small and most of experiments are verified. There is no opportunity to train teamwork capacity involving engineering and electronic products.

The Application of Advanced Teaching Technology is Still Lacking. In addition to the introduction of multimedia teaching and simulation software, there is almost no network and other internet tools, so the information on this program is limited and it is not beneficial for students to expansion the classroom and going on to learn.

The Low Participation of Students in Classroom Teaching is Mainly Due to the Limited Time of Course Hours and the Negative Learning Attitude of Students'. To some extent, there is almost no students' voice, which is not conducive to students' positive and innovative thinking.

\section{Reform Ideas and Methods}

Classroom Teaching Reform of Digital Electronic Technology Based on CDIO concept. Classroom teaching practice of digital electronic technology based on CDIO concept mainly focus on the teaching mode, innovative experimental system and evaluation system. CDIO is the abbreviation of Conceive, Design, Implement and Operate ${ }^{[1]}$. Based on the actual product from the conceiving, $R \& D$ to operate, even to the end of life cycle (life cycle), namely regarding an actual product as the carrier, let students learn engineering as a mode of active attitude, practice and organic link between the courses. It provides students with an engineering education based on real products and emphasized the engineering foundation and the process of real products from "conceive-design-implement-operate".

In the "conceive" phase of digital electronic technology course teaching, teachers not only need to help students clear the different demands at the different using situations of the product or different users may be concerned about, but also need to help students clear shortcomings of the product itself at the current market. In the "design" phase, teachers not only need introduce the knowledge and skills of making the products, but also train abilities of students to verify the function of every components, read schematics and design unit circuits. It is required to combine exercises in class with instruction after class, to cater for students' different cognitive abilities, and to further expand their knowledge and innovation. In the teaching process, teachers combine the project with actual products, the related scientific research content, students' innovation project, so that each link can promote and improve each other. It requires the whole teaching process to pay attention to training the ability of the team cooperation and enhancing the students' spirit of humanities.

This kind of classroom teaching based on the product life cycle embodies the characteristics of CDIO engineering education. Evaluation methods focus on knowledge, skills and attitude, reflecting the soft and hard abilities. Learning and implementation of CDIO have been carried out in our university for many years. Since September 2011, we have carried out the practice of CDIO engineering teaching in the digital electronic technology program, collected information of CDIO extensively, learned advanced teaching ideas from various channels, and continuously improved and adjusted teaching methods and evaluation methods. We improve the projects and take various measures to improve the enthusiasm of learning of students and stimulate students' awareness of innovation. We get much experience and lessons and find the idea of CDIO is more suited to the digital electronic technology program ${ }^{[2]}$.

The Impact of Micro-lecture on Classroom Teaching. Micro-lecture has been widely recognized as a new type of educational information resources due to its characteristics: short and pithy, highlight the theme and be interactive well since "micro-lecture" was been put forward in China in $2011^{[3]}$. Practice and application of micro-lecture are also quickly launched, which led to all levels of micro-lecture competitions that carried out throughout the country in order to promote 
the integration of information technology and subject teaching. Under this background, our teaching team completed the plan of making the micro-lectures for the digital electronics technology program in 2014, we implement and finish the plan in 2015. Implementation of the program has recognized by experts and our program was awarded as "provincial level high-quality open course in Zhejiang province". We have finished all micro-video shooting, editing, uploading and opening to the public. The construction of micro-lecture of digital electronic technology was completed.

The urgent question before us is how to make good use of role and combine with the teaching idea of CDIO in classroom teaching, to achieve complementary results, to further stimulate students' enthusiasm for learning, and constantly improve the effect of classroom teaching, increase student participation. We have a try to make a combination of micro-lecture based on CDIO concept.

Organization and Implementation of Classroom Teaching Combined with Micro-lecture Based on CDIO Concept. In classroom teaching of digital electronic technology based on CDIO projects, the real electronic products as a carry, from the identification of projects, select the required functions or indicators, introduce the function of required components, related functional circuit design, and the final total the installation and debugging of the circuit. What content is suitable for students to learn by themselves, or to preview or review, what content is suitable to teach or explain by teachers, what content is suitable for students to discuss, how teachers involved in the discussion of students, how to use resources on the internet platform, how to combine platform information and comprehensive evaluation of the curriculum, which are all worth exploring and practice.

Based on project teaching we have implemented for many years, We regard real electronic products as a carrier and use all kinds of teaching method flexibly in classroom, such as heuristic method, case method, demonstration, speech, discussion and other teaching methods to deal with CDIO teaching in all aspects of the key, difficult, and skills training and innovation practice. We introduce micro-lecture timely and make use of the short video (5-15 minutes) to solve the problems of most of the knowledge and highlight the key and the difficult of the course. Teachers offer the knowledge as the content of preview at the prepare stage and assign students to watch the relevant micro-lecture (it is not necessary for students to understand completely). Let students to prepare and write down three types of questions for discussion in classroom ${ }^{[4]}$. The first type of questions is "showing". This means this type of questions you have understood completely and you have solved the questions. Let you have the chance to show what you have gotten from the micro-lecture. The second type of questions is "testing". This means give other students a test. You prepare questions for other students that you think they are very important. The third type of questions is "helping". This means "helping me". When you meet the problems what you cannot solve, you write down and take them to the classroom to let other students or teacher help you. Each student takes questions into the classroom. When teacher comes to the knowledge what they have previewed, teacher can reduce the teaching time and leave time for students' group discussions. In the discussion, students discuss the questions what they have taken into. Teacher can solve the questions what the students cannot solve by themselves.

This method is different from the flipped classroom mode. The flipped classroom mode is learning before teaching. This "learning" refers to the students must be high quality to complete the learning task after class. It takes a long time for students to learn, however teacher no longer explain the teaching content, just let students ask questions and discuss. The mastery of learning is handed over to the students in the flipped classroom, besides, teachers and students need a higher ability of learning, information skills, problem awareness and psychological quality. Only in this way, the flipped classroom mode can really become effective interactive teaching form and achieve teaching and learning win-win. The efficiency of the flipped classroom depends on the high performance of teachers, students and the teaching media. If an aspect cannot do this, the teaching effect will be greatly reduced. According to the current educational environment of our university, the teaching subjects are large and intensive and the ability of self-learning and self-control is generally lack, the flipped classroom mode is difficult to achieve the desired effect.

It is different from the flipped classroom mode in our classroom teaching. The "learning" pre-class 
is equivalent to the preview in the traditional classroom, but the content of preview is one or several micro courses (short video), which is more open, more brief and make the target more accurate. We don't ask all students to understand knowledge completely and the three aspects questions we ask students to record can be very simple and the number of questions can be more or less. We use the concept of CDIO in classroom teaching and the learning of knowledge is not based on self-study of students and teachers still need to explain the knowledge. Due to the previous preview, teachers can leave a small part of time to organize discuss and solve some typical problems. The advantage of this is that we not only make good use of the advantage of the micro-lecture to finish the preview of the key knowledge, but also reduces the requirement of the preview, this will not let the students have a lot of pressure or frustration because of meeting great difficulty. Meanwhile students can learn knowledge with their own questions and change the passive learning to active learning. It makes students take the initiative to participate classroom discussions because the issues discussed are their own asked, make the discussion more effective. It not only improves the enthusiasm of students' learning and comprehensive ability, but also can enhance teaching effectiveness.

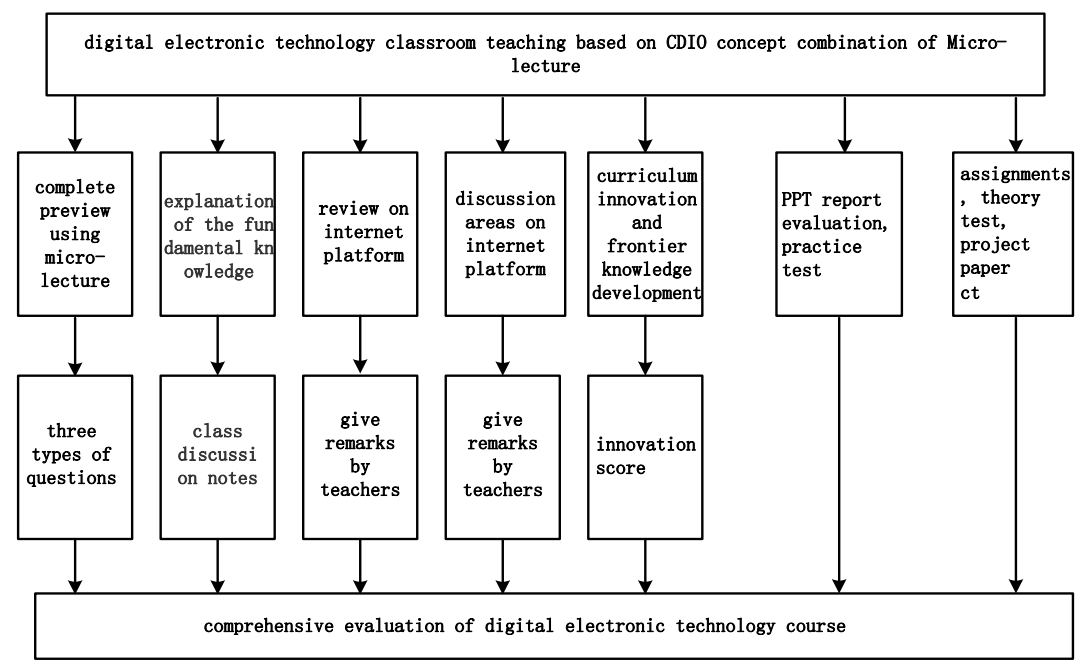

Figure.1 Finite comprehensive evaluation of digital electronic technology course

Evaluation of Digital Electronic Technology Classroom Teaching Based on CDIO Concept Combination of Micro-lecture. We implement the whole process and open evaluation system. As shown in Fig. 1, the evaluation is focus on knowledge, skills and attitudes, which reflect the soft and hard skills based on CDIO concept. We regard the preview, classroom participation, unit test, PPT report, practical tests, and team cooperation etc. as the parts of courses grades. We pay attention to the attitude in the classroom teaching, encourage the innovative spirit of students and stimulate students' creative consciousness. We consider the relationship between the results of team members to reflect the importance of teamwork and it is beneficial to cultivate the overall concept of students. It makes students have good interpersonal skills and teamwork.

\section{Conclusion}

Through the teaching reform and practice, students received the engineering training of the course of digital electronic technology. The ability of system engineering, self-learning ability, teamwork ability has a more obvious improvement. Awareness of learning on internet has made great progress. At the same time, the implementation of the new teaching method also led to the improvement of teacher's ability. Teaching benefits teachers as well as students.

\section{Acknowledgements}

This research was financially supported by Zhejiang University of Water Resources and Electric Power Teaching Reform Project Funding. Project number is KG201606. 


\section{References}

[1] Zhou Wujie, In the CDIO Mode of Electrical Technology Exploration, Modern Industrial Economy and Informationization[J],83,2014,Vol.9.

[2] Yang Qi-yao, etc, Project-based Reform and Practice of Electronic Technique on CDIO[J],J.Zhejiang Univ of Wat. Res \& Electric Pow., 2014(3).

[3] Hu Tiesheng, Huang Mingyan, Li Ming, The Three Stages of Micro-lecture Development and Its Enlightenment, Journal of Distance Education[J], 36-41,2013, Vol.4.

[4] Zhang Xuexin, PAD class, Fudan Education Forum, 2014, Vol.12, No.5. 